\title{
DELTA UNIVERSITY SCIENTIFIC JOURNAL \\ The repercussions of the Corona pandemic on the tourism sector between reality and hope
}

\section{Miloud benkhira ${ }^{1}$, mesmoua asma ${ }^{2}$, saida tayeb ${ }^{3}$}

${ }^{1}$ Phd student,Financial and Accounting Sciences Department, Hassiba Ben Bouali University, Algeria

${ }^{2}$ Phd student, Department of Commercial Sciences, Hassiba Ben Bouali University, Algeria

${ }^{3}$ Associat Professor A, busissess and management Department, ahmed zabana University, Algeria

Keywords:

1- World

Tourism

2- International

Domestic

Tourism

3- COFED-19

Crisis

\begin{abstract}
Through this study, we showed the impact of the Coronavirus on the global tourism sector, which has caused huge losses to the virus. Global tourism is one of the most affected sectors during the Coved-19 crisis, in the absence of a vaccine.

The recovery model predicts a cumulative decline from $\$ 3$ trillion to $\$ 8$ trillion before tourism spending returns to pre-pandemic levels
\end{abstract}

The 2019 level of $4 \%$ growth is expected to be only after 2023, which is expected to reach $3.9 \%$ according to the latest economic tourism forecast. The sector's recovery is expected to be gradual, such as the re-opening of the various economies, in which domestic tourism will return to pre-crisis levels about one to two years of external travel

\footnotetext{
تاعيات جائحة كورونا على قطاع السياحة بين الواقع والمأمول

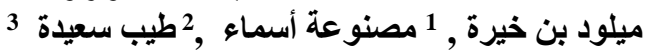

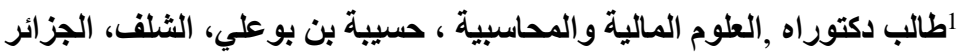

2طالب دكتوراه، علوم تجارية ، حسيبة بن بوعلي ، الجزائر

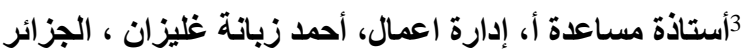

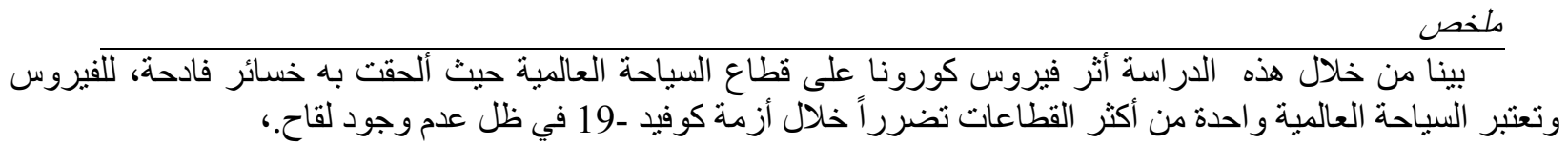

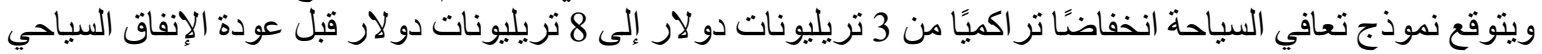

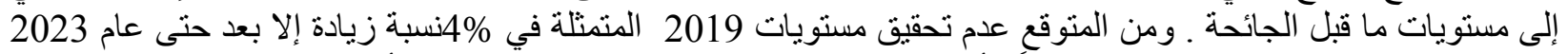

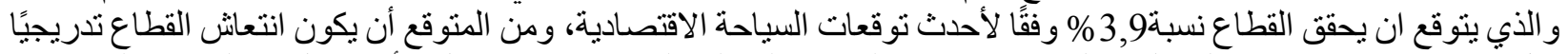

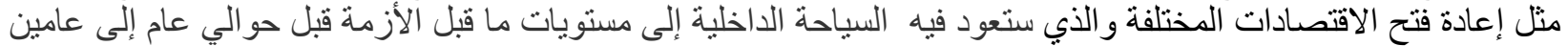

الكلمات الإفتتاحية : السياحة العالمية، السياحة الدولية السياحة الداخلية ، ازمة كوفيد-19
} 


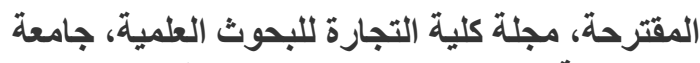

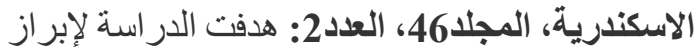

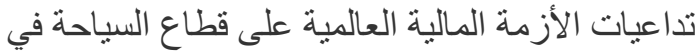

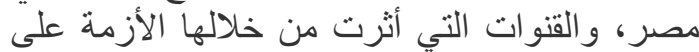

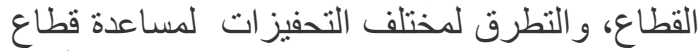
السياحة، في ظل السيناريو هات المختلفة لتطور الأزمة

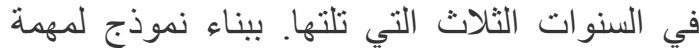
الطلب السياحي من خلال تقدير الطلب على السياحة النياء في مصر خلال الفترة من خلاد 1990 إلى 2008 على الطى

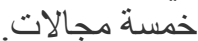

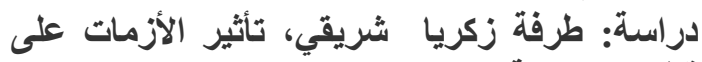

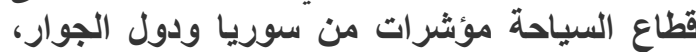

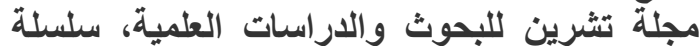

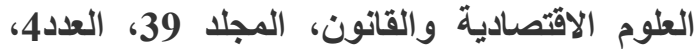

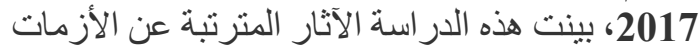

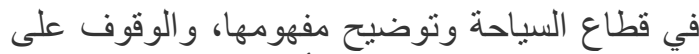

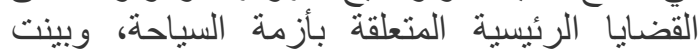

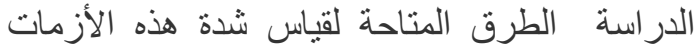

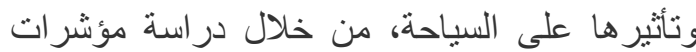

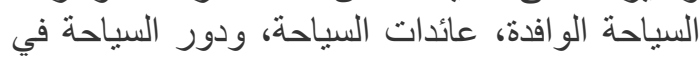

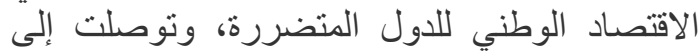
وجود علاقة بين طبيعة وشدة الأزمة وتأثنير ها على للى التى

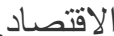

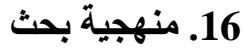

تم الاعتماد على فيهذه الدراسة على المنهج الوصفي

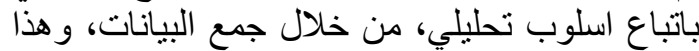

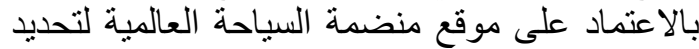

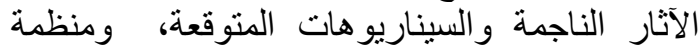

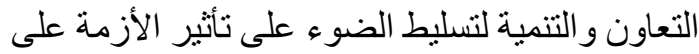

الاقتصاد عالميا.

17. 17 النتائج

المحور الاول : واقع تأثير جائحة كورونا على قطاع السياحة العالمية الماول

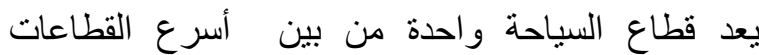

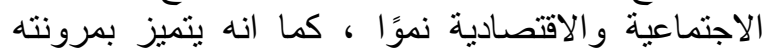

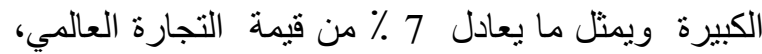
كما انها ساهمت في خلق ملايين الوظائف سواء بـاء بشكل

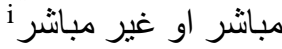

وتعد صناعة السفر من جائحة فيروس كورونا

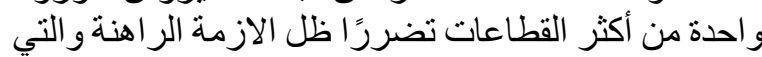

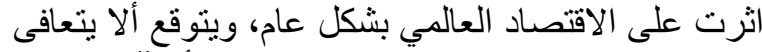

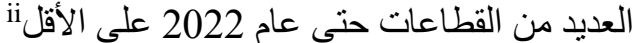

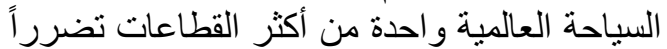
خلال أزمة كوفيد -19 ييتوقع نموذج تعافي السياحة المناع

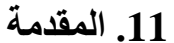

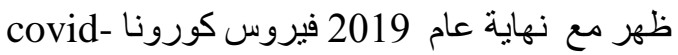
19، والذي تحول من ازمة صحية الى ازمة القية اقتصادية

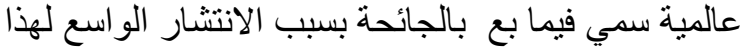

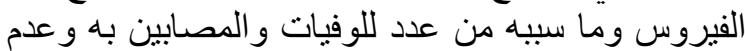

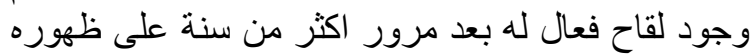

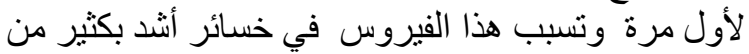
الأزمات السابقة كأزمة السارس في عام في في 2009 و والأزمة المالية 2009 و أحدث تغيير اتمات جوهرية في صناعة السفر

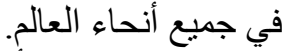

كما تركت الأزمة الصحاء الصحية العالمية الحكومات في

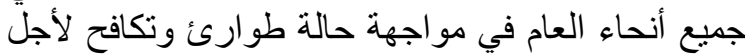

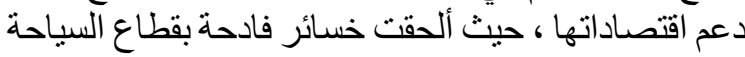

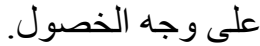
12. مشكلة الدراسة

نظر الما تعرض له الاقتصاد بصفة عامة و الصدمة

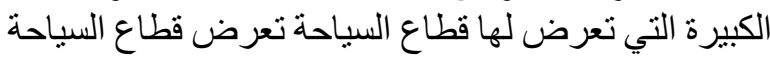

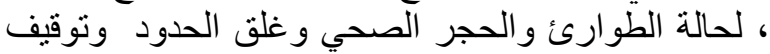

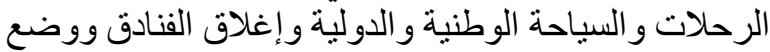

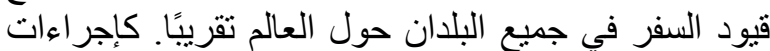

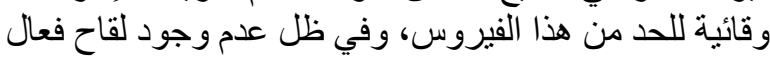
لحد الساعة، نطر ح الإشكالية التالية:

\section{ما واقع ومستقبل لقطاع السياحة العالمية في ظل العلة}

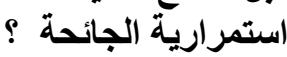
13. أهداف البحث: تكمن أهداف البحت في:

• الوقوف على آثار وتبعات فيروس كورونا على قطاع السياحة. • التعرف على مدى تأثير فيروس كرونا على قطاع السياحة في العالم

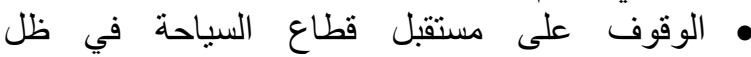

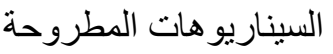
• الوقة الوق على توقعات الآجال للمكنة لتعافيه من هذه

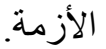
14. أهمية البحث: تكمن أهمية البحت في:

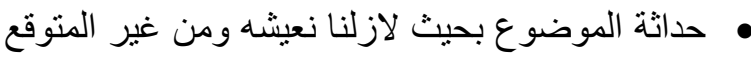
انتهاء الجائحة في الوقت المستقبل القريب.

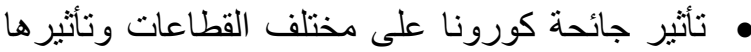
الكبير على قطاع السياحة بالنسبة للاقتصاد العالمي كافة.

15. درسات سابقة

دراسة: سعيد عبد العزيز علي عثمان، محمد جابر العابر

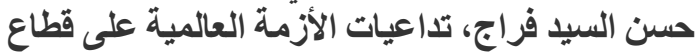

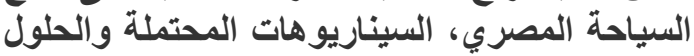


مليون سائح دولي أقل من الو افدين مقارنة بالفترة نفسها من

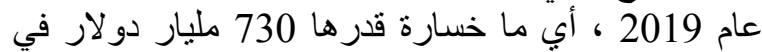

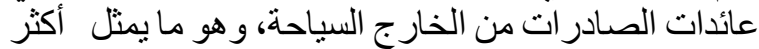
من ثمانية أضعاف الخسارة قطاع السياحة جراء الثاء الأزمة الاقتصادية العالمية عام 2009.فيما شهدت منطقة الفيانة آسيا

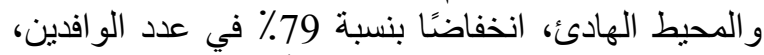

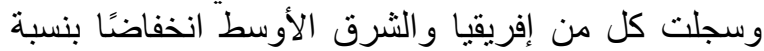
69 6بينما شهدت أوروبا (68\% و و انخفاض بما يعادل 65٪

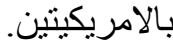

لا تزال البيانات المتعلقة بإنفاق السياحة الدولية

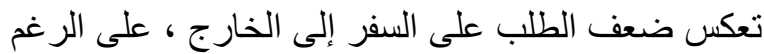

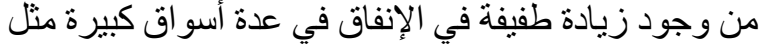

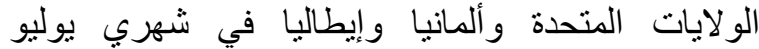
و الثكل المو الي يوضح التطور في مختلف المناطق.
انخفاضًا تر اكميًا من 3 تريليونات دو لار إلى 8 تريليونات

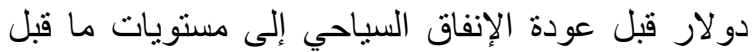
COVID-19. iii

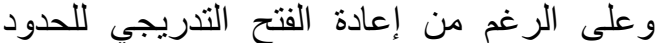
الدولية في أواخر مايو ويونيو ، إلا أن الانتعاش في في السفر

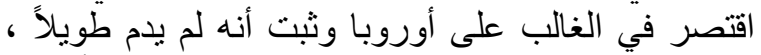

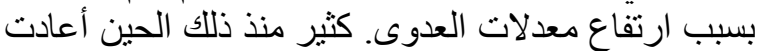

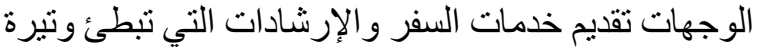
الانتعاش الضعيفة بالفعل فئل

و هو ما أثر بشكل كبير عدد السياح الو افدين الدوليين

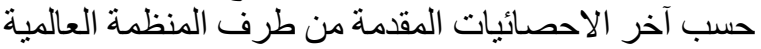

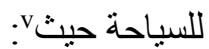
تسبيت الجائحة في انخفض بنسبة 70 \% في الأشهر الثمانية

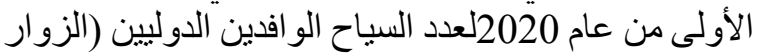

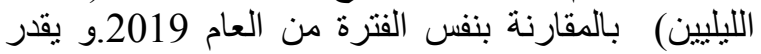
الانخفاض في الفترة من يناير إلى اوت 2020 يمثل 700

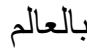

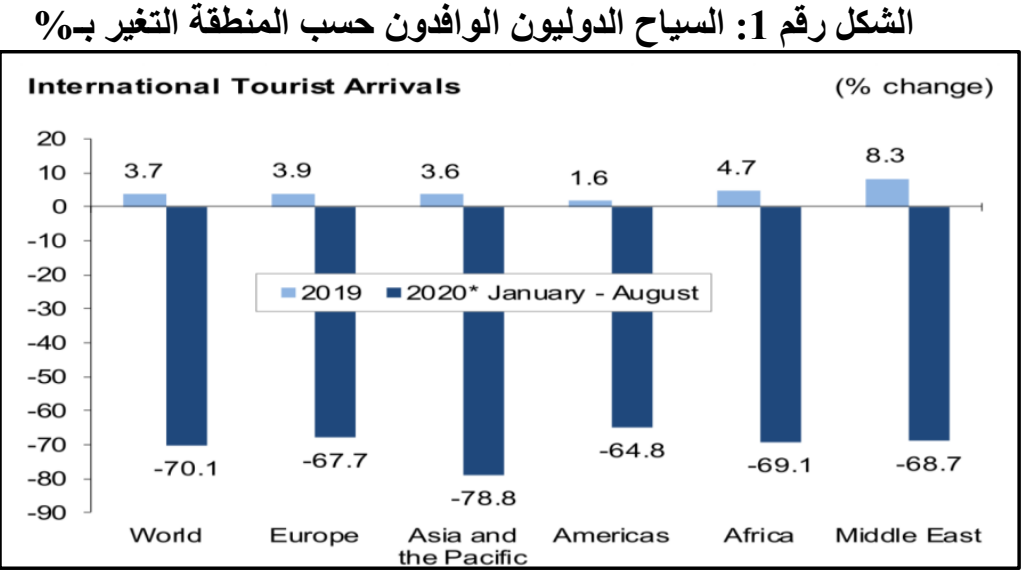

Source : World Tourism Organization, World Tourism barometer, Volume 18 - Issue 6 (version 27/10/20,p1

الارتفاع الكبير في عدد السياح الدوليين للشهرين، جويليا

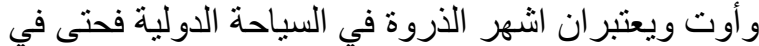

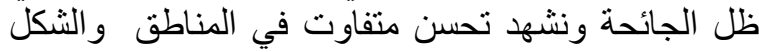
التالي يوضح ها بالتفصيل.
فالطلب على السياحة انخفض بشكل كبير وبالنظر

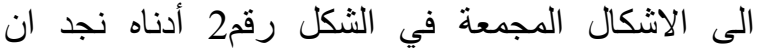

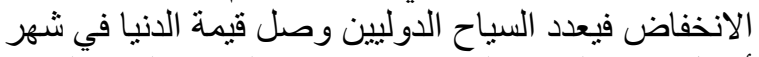

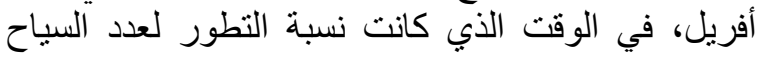

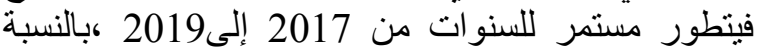

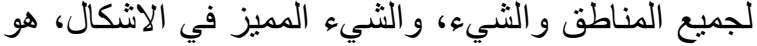
الثكل رقم2: التغير في عدد السياح الدوليون الوافدون حسب المنطقة حسب المنطقة بالمليون نسمة 


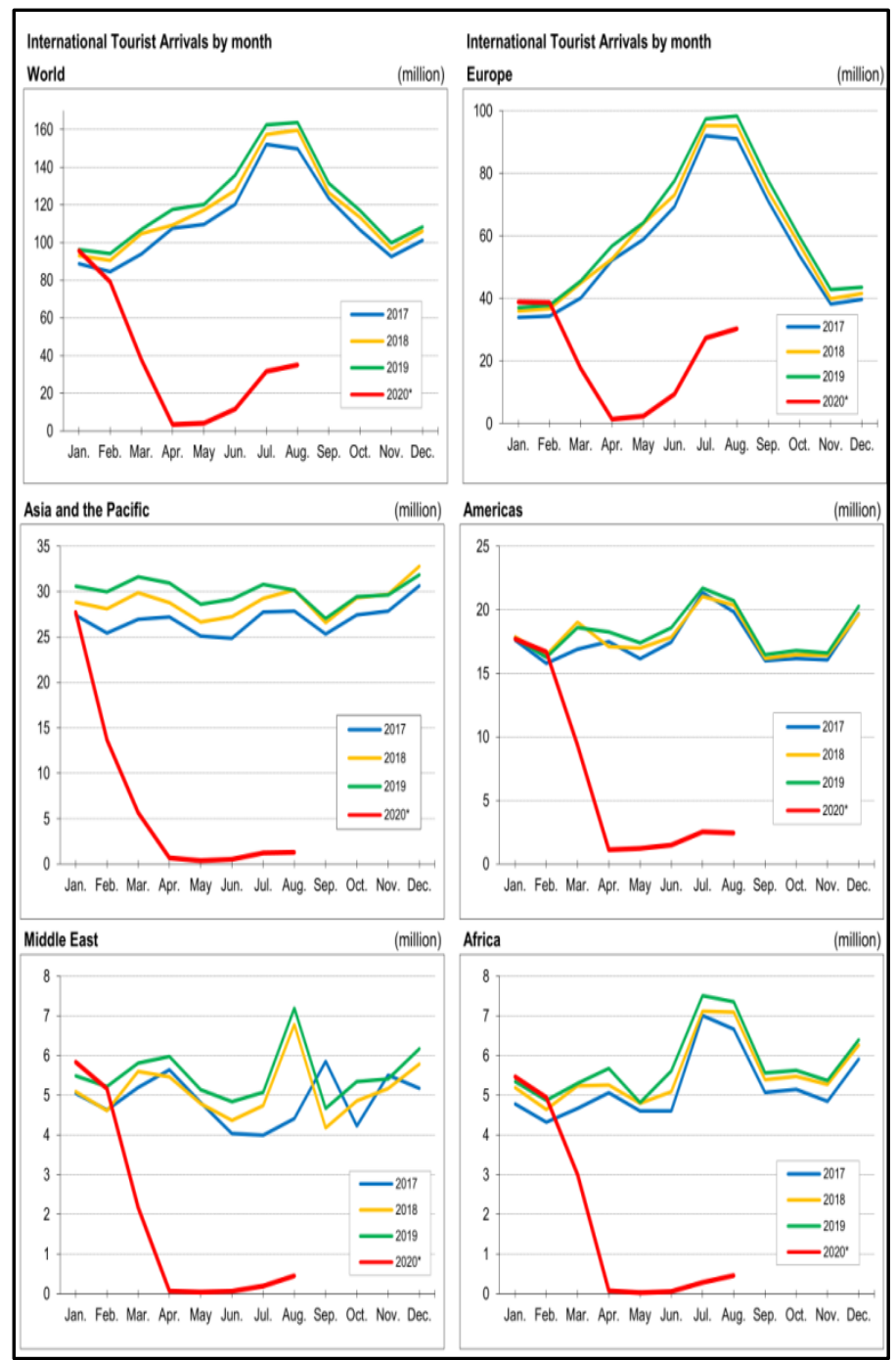

source: World TourismOrganization, World Tourism barometer, Volume 18 - Issue 6 Annex - 5 (version 27/10/20,p

الحدود و وفرض الحجر الصحي وهو ما أثز بنسبة تفوق

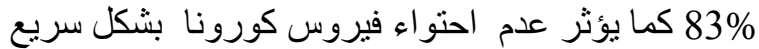

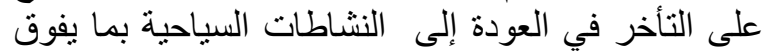

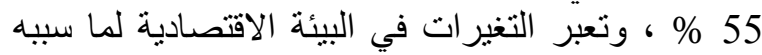

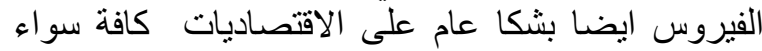
المتقدمة منها او غيرها هالأثير على تعافي قطاع السياحة بحو الي 40\%

بالإضافة الى الآثار المترنبة عن عدموجود استجابة منسقة فيما بين بين الدول و الثنكل النالي يلخص عنم ذللك:
المحور الثاني: تعافي قطاع السياحة

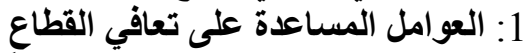

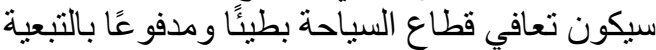

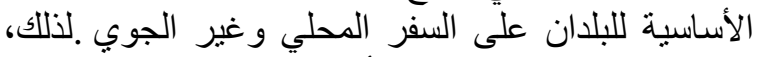
يجب على البلدان المختلفة أن تستعد لمنحنيات التهان التعافي

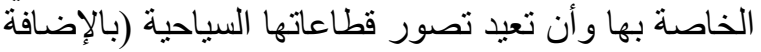

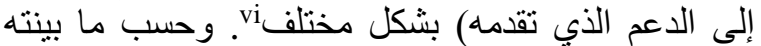

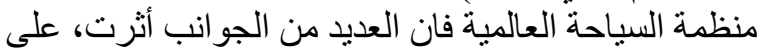

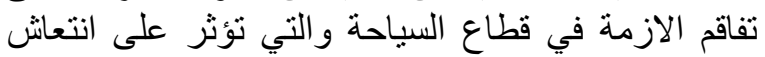

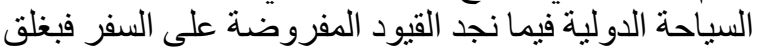

\section{الثكل رقم3: العوامل الرئيسية التي تؤثر على انتعاش السياحة الدولية}




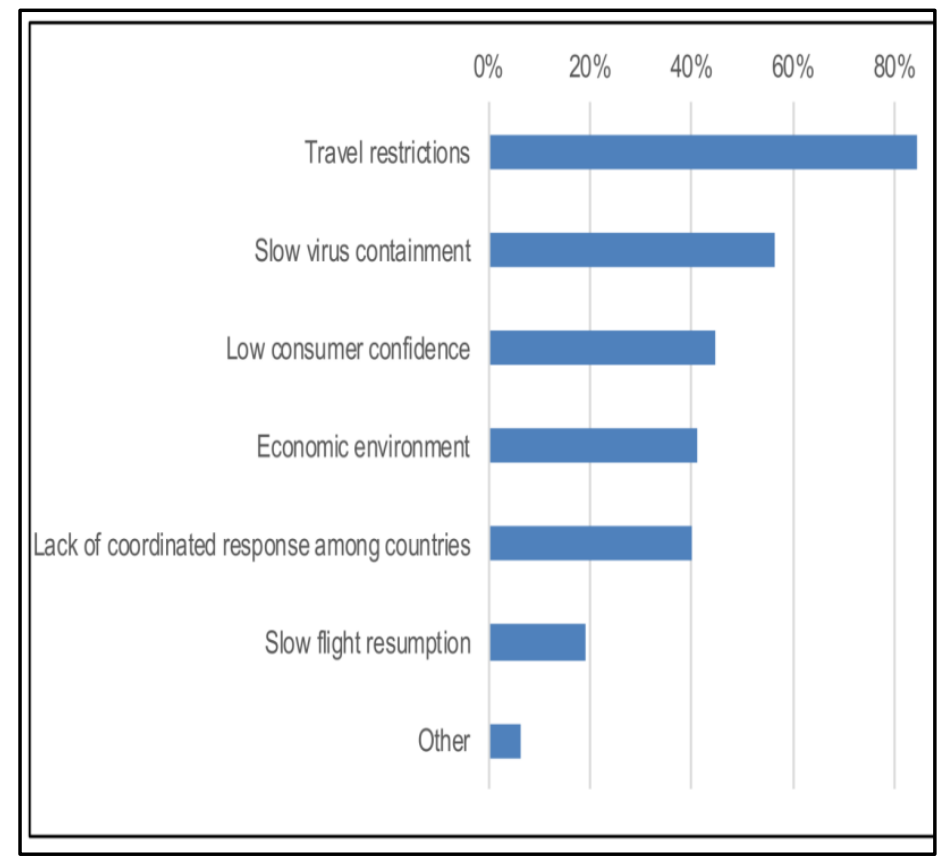

Source :World Tourisme Organisation, World Tourisme baromètre, Volume 18 • Issue 6 (version

$1127 / 10 / 20, p$

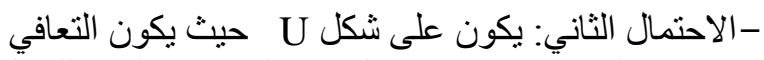

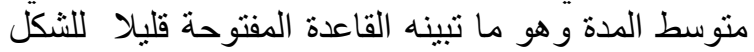
على عكل الاحتمال الاول مأول

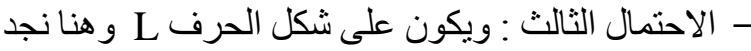

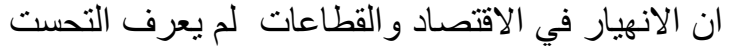

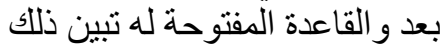

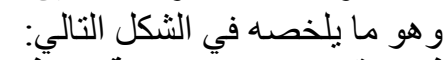$$
\text { الشكل رقم 4: السيناريوهات المتوقعة لتعافي الاقتصاد حسب سرعة فئ التعاقفي }
$$

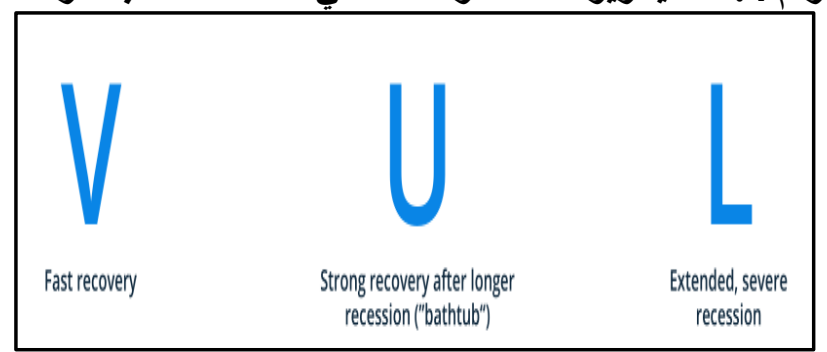

Source :Alexandra Rotar,eremiah LasquetyReyes, Christoph Blumtritt ,and other, ECONOMY COMPASS 2020,p14

للفيروس، مما منع فتح الحدود و وعلى الرغم من رفع قيود

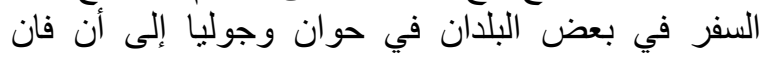

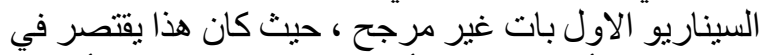

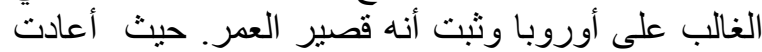

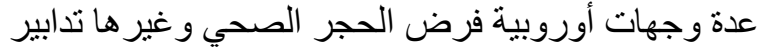
استجابة لحالات COVID-19 المتز ايدة شهري جوضي جويليا

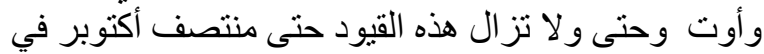

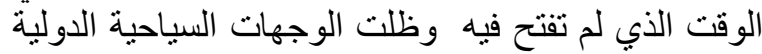

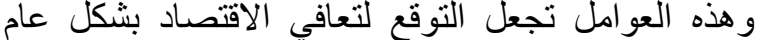
وقطاع السياحة بشكل خاص يتبع الاحتمالات الثيلات التاث التالية:

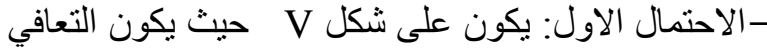

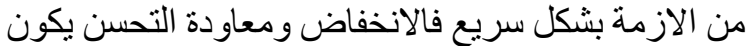
بسر عة الأمة 
• (السيناريو 3: -78\%): انخفاض بنسبة 78\% على التى

أساس فتح الحدود الدولية تدريجيا وتخفيف قيون النئ السفر فقط

$$
\text { في ديسمبر. }
$$

ونجد أنهار غم العودة الى التعافي حيت كانت احتمالية حدوت

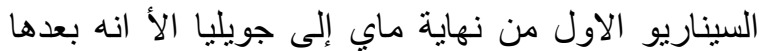

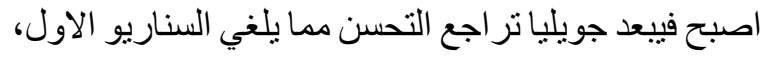

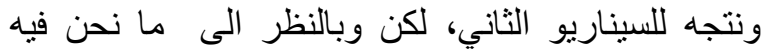

وبالوصول إلى شهر نوفمبر

رسمي ولم يصر ح بشكل رسمي بوجئ بود لقاح فعال سيسوق،

فإننا نتجه للسيناريو الثالث.

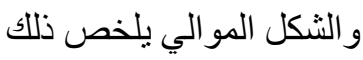

الثكل رقم5: السيناريوهات المتوقعة لتعافي السياحة الدولية

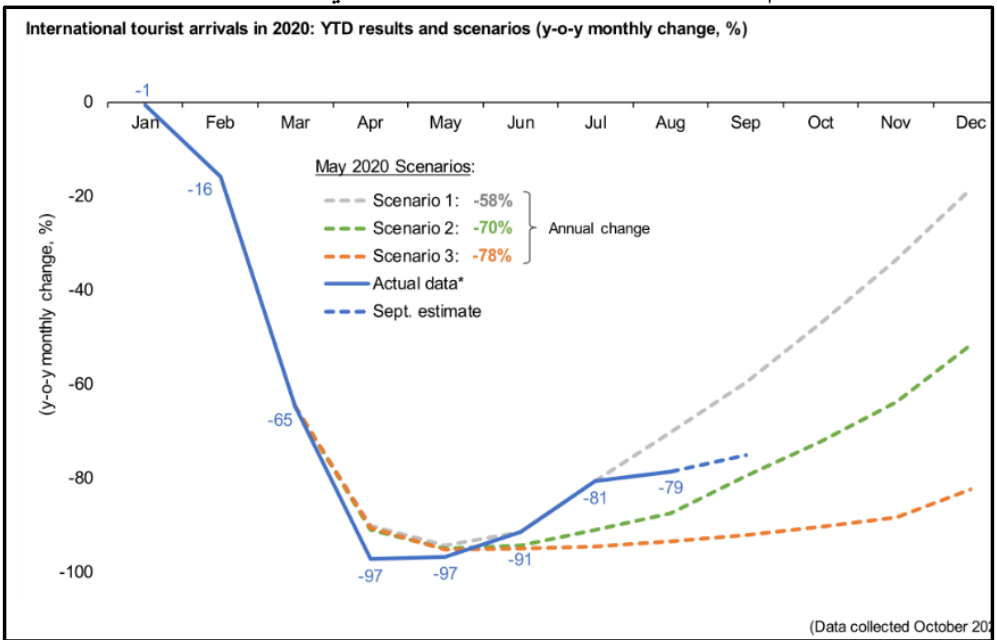

Source :World Tourism Organization (UNWTO), AlUla Framework for Inclusive Community Development through Tourism, Madrid, Spain,First published: 2020,p40

حيث ستعود السياحة الداخلية إلى مستويات ما قبل

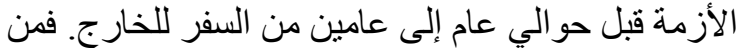
المنوقع أن يتعافى السفر المحلي بشكل أسرع من الفنادق.

ومن المتوقع أن تنتعش السياحة الدولية بحلول

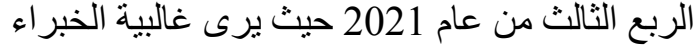

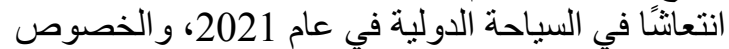

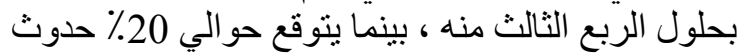

ذللك في عام 2022 فقط. X. و هو ما نلاحظه من الثنكل التالي:
الرئيسة في أجز اء أخرى من العالم مثل الصين و الولايات المتحدة مغلقة. و الثكل التالي يوضح السيناريو هات الثناتلاث

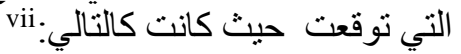
• • (السيناريو 1: -58٪):الفتح التنريجي للحدود الدولية وتخفيف قيود السفر في أو ائل جويلية ما يسبب النيب انخفاض للاض بنسبة 58\%. • • (السيناريو 2: -70\% (70) ): على أساس فتح الحدود الدولية تدريجيا وتخفيف قيود السفر في أو ائل سبتمبر. الامر الذي الذي التئ يؤدي الى انخفاض بنسبة 70\% ـ

\section{3}

:التوقعات المستقبلية لتعافي القطاع:

للتوقعات المستقبلة سيناريو هان الثنان الاول متثنائم

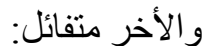
الاول: سيناريو التعافي المتفائل : يجمع بين الاحتواء

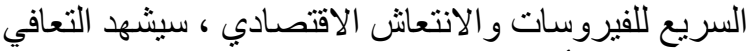

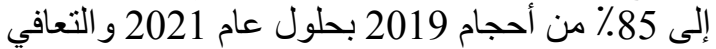
الكامل بحلول عام 2023 في الثاني: السيناريو المتثائم:

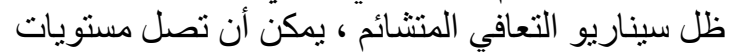
2021 إلى 60 في المائة من عام 2019 ، مما يزيد من التحن تأجيل الانتعاثن 


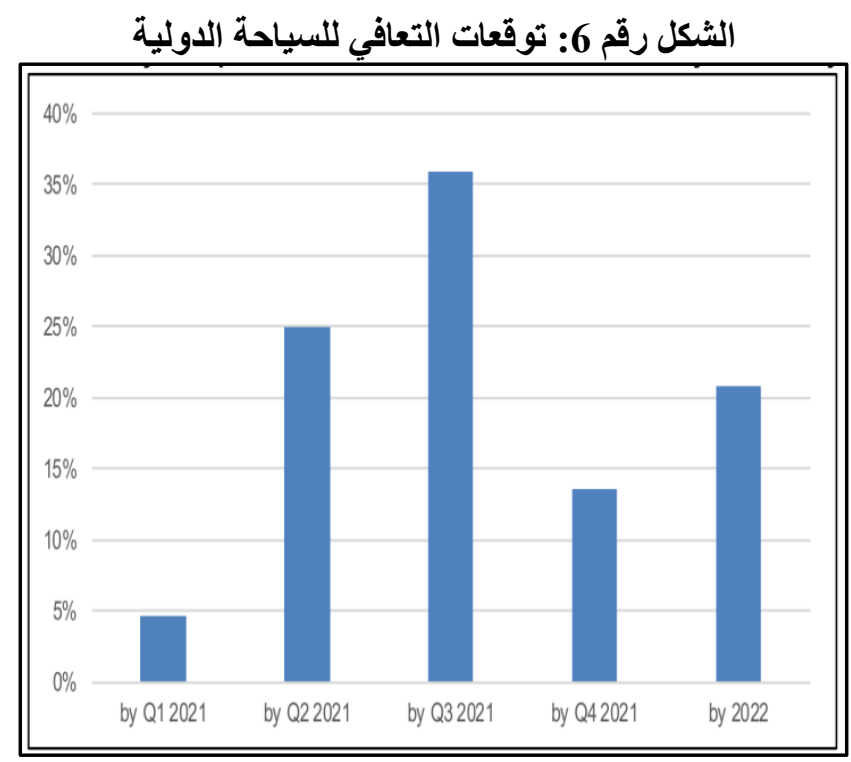

Source :World Tourism Organization, World Tourism barometer, Volume $18 \bullet$ Issue 6 (version 27/10/20,P10

الدولية بنسبة اكبر حيت تقارب75 \% مقارنة بسنة 2019،

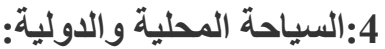
بينما كان التأثير على السياحة المحلية (الداخلية) اقل بكيث

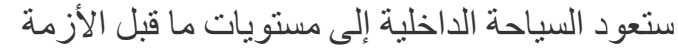

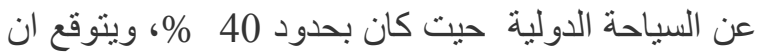

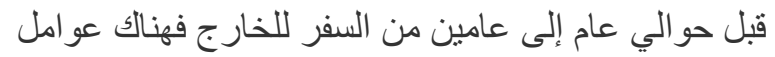

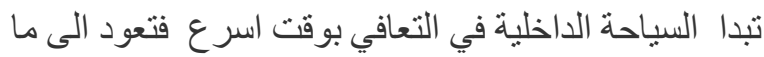

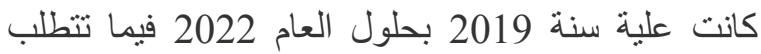

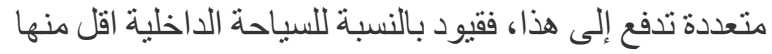

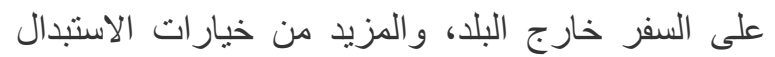

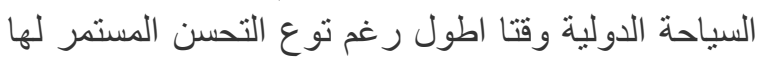

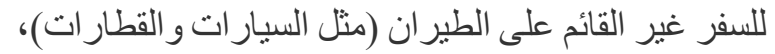

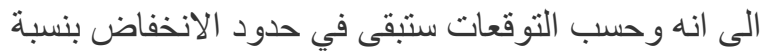

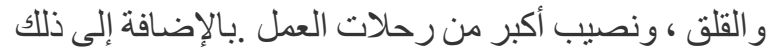

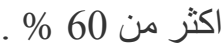

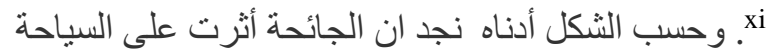
الثكل رقم7: التعافي في السياحة الداخلية والاولية التية

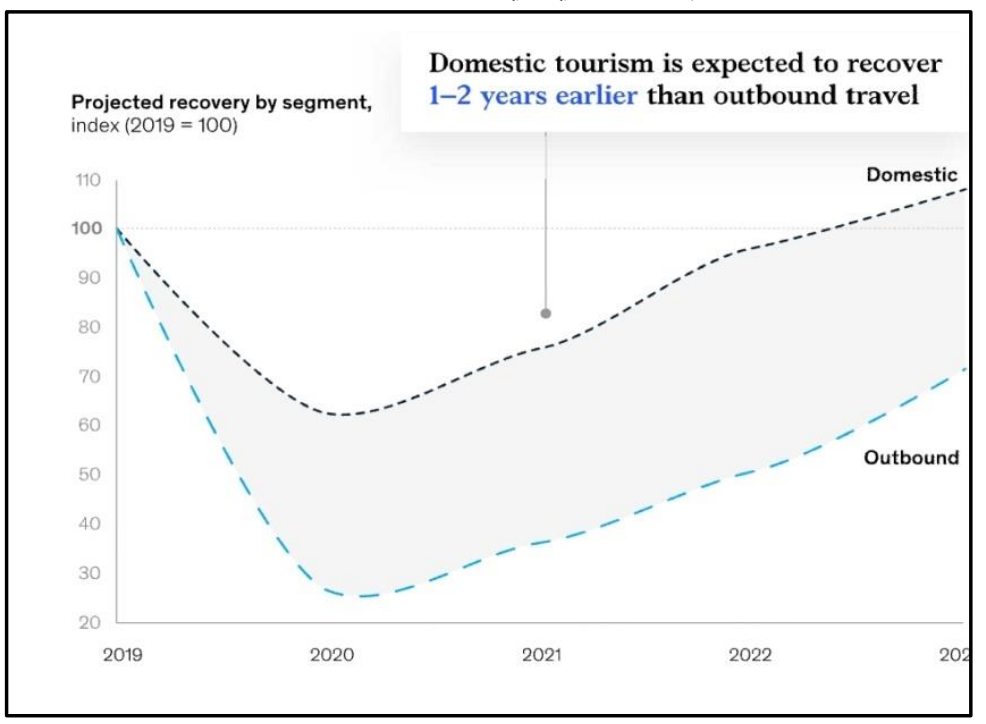

Source :https://www.mckinsey.com/industries/travel-logistics-and-transport-infrastructure/ourinsights/covid-19-tourism-spend-recovery-in-numbers consulté le 22/11/2020 فيما يتوقع آخرون أن عودة إلى مستويات ما قبل الجائحة لعام 2019 لن تكون ممكنة قبل عام 2023. ويتوق 
النمو على ما كانت عليه سنة 2019 بحلول العام 2023,

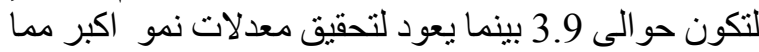

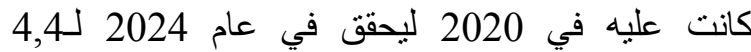

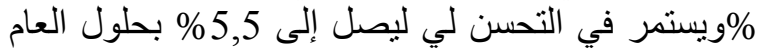
2030 و الثكل التالي يوضح ذلك لك التي
نسبة العودة إلى مستويات عام 2019 في عام 2023 أو مالو ما

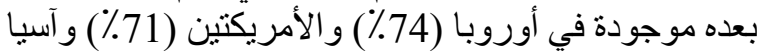

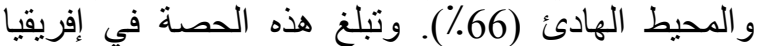

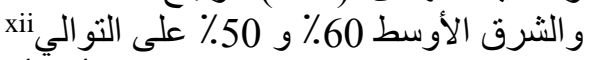

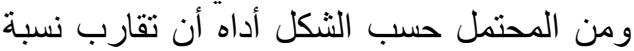
الثكل رقم8: توقعات نسبة النمو في السياحة العالمية

Source :https://www.mckinsey.com/industries/travel-logistics-and-transport-infrastructure/ourinsights/covid-19-tourism-spend-recovery-in-numbers consulté le 22/11/2020

• • • مأثر فيروس كورونا على عدد السياح القادمين ونفقاتهم

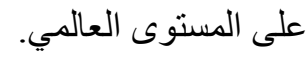

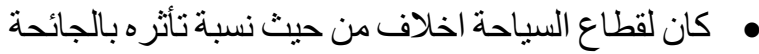
وهذا راجع إلى اعتماد اقتصاد البلدان على قطاع السياحة في تنشكيل الناتج المحلي.

ومن خلال النتائج المتوصل لها لضان النع التوصيات التالية:

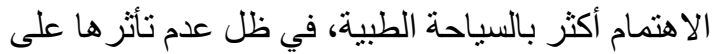

$$
\text { عكس باقي الانو الع العباع }
$$

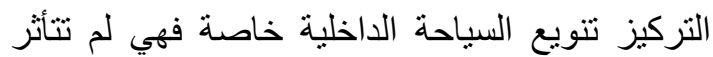

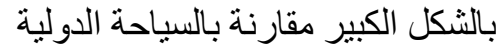

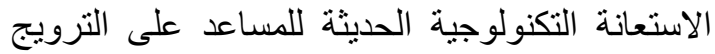

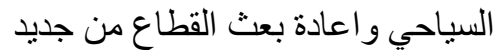
التفكير في ما بعد الازمة والتعامل السريع مع التئ الوضع الجديد واستقبال السياح. الاسساهمة في توفير حوافز بتسهيل السفر ، وتعميم

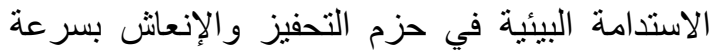
لتحفيز الطلب. تعزيز التسويق و الفعاليات و الاجتماعات و الندوات و الحفلات وجميع النشاطات الجاذبة للسياح. • العمل على وضع السياحة المستدامة بشكل ثابت التئ في كل الأعمال الوطني للاول.
18. توصيات

كوفيد -19 - أزمة غير مسبوقة وفرصة للتحول السياحي، نظرًا لأنتا نعيش في واحة فيرة من أكبر الأزمات

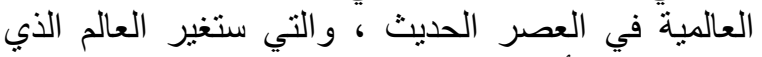

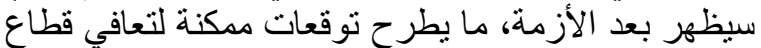

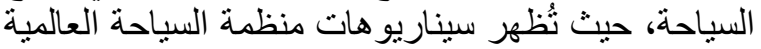

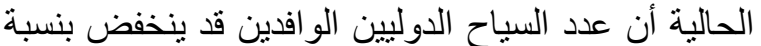

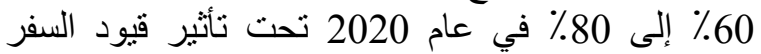

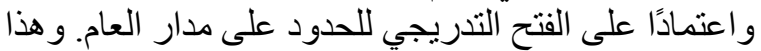
من شأنه أن يترجم إلى دالى 850 مليون إلى 1.1 مليار سائح دولي أقل و 910 مليار دولار إلى 1.2 تريلي التيليون دولار

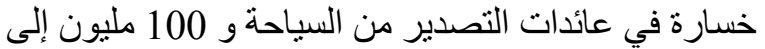

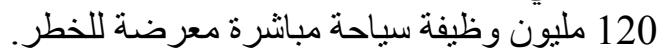

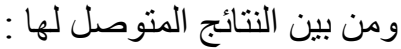
• يواجه قطاع السياحة تحدي كبير للعودة بالسياحة

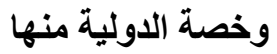
• • تأثر قطاع السياحة عالميا بفيروس كورونا ولا يتوقع حدوث تحسن في المستقبل القريب • أدت الازمة لانخفاض عدد السياح الأجانب بثدة بداية

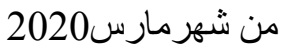
• • غيرت لمنظمة السياحة العالمية التوقعات الأولية في ظل استمر ارية القيود المطبقة. 
insights/covid-19-tourism-spend-recoveryin-numbers consulté le 22/11/2020

${ }^{\mathrm{ix} h t t p s: / / w w w . m c k i n s e y . c o m / i n d u s t r i e s / t r a v e ~}$ l-logistics-and-transport-infrastructure/ourinsights/covid-19-tourism-spend-recoveryin-numbers consulté le 22/11/2020

${ }^{\mathrm{x}}$ World Tourism Organization, World Tourism barometer, Volume 18 Issue 6 (version 27/10/20,P10 xi

https://www.mckinsey.com/industries/travel -logistics-and-transport-infrastructure/ourinsights/covid-19-tourism-spend-recoveryin-numbers consulté le 22/11/2020

xii World Tourism Organization, World Tourism barometer, Volume 18 Issue 6 (version 27/10/20,P10
' World Tourism Organization (UNWTO), AlUla Framework for Inclusive Community Development through Tourism, Madrid, Spain,First published: 2020,p212

ii https://www.businessinsider.com/travelindustry-one-of-the-hardest-hit-bypandemic-2020-7? IR=T consulté le $22 / 11 / 2020$

iiihttps://www.mckinsey.com/industries/trave l-logistics-and-transport-infrastructure/ourinsights/covid-19-tourism-spend-recoveryin-numbers consulté le 22/11/2020

${ }^{\text {iv }}$ World Tourism Organization, World Tourism barometer, Volume $18 \cdot$ Issue 6 (version 27/10/20,p

${ }^{v}$ World Tourism Organization, World Tourism barometer, Volume $18 \bullet$ Issue 6 (version 27/10/20,p1

${ }^{v i}$ https://www.mckinsey.com/industries/trave 1-logistics-and-transport-infrastructure/ourinsights/covid-19-tourism-spend-recoveryin-numbers consulté le 22/11/2020

vنظمة https://news.un.org/ar/story/2020/05/105449 JUN, 20 تاريخ النثر 7 ماي/2020 2020 2020

viiihttps://www.mckinsey.com/industries/trav el-logistics-and-transport-infrastructure/our- 